\title{
Cellular and radiobiological effects of carbonic anhydrase IX in human breast cancer cells
}

\author{
ANTJE GÜTTLER $^{1}$, KATHARINA THEUERKORN $^{1,2}$, ANNE RIEMANN $^{3}$, HENRI WICHMANN $^{1}$, \\ JACQUELINE KESSLER $^{1}$, OLIVER THEWS ${ }^{3}$, MATTHIAS BACHE ${ }^{1}$ and DIRK VORDERMARK ${ }^{1}$ \\ Departments of ${ }^{1}$ Radiotherapy and ${ }^{2}$ Internal Medicine I, and ${ }^{3}$ Julius Bernstein Institute of Physiology, \\ Martin Luther University of Halle-Wittenberg, D-06112 Halle (Saale), Germany
}

Received November 5, 2017; Accepted January 4, 2019

DOI: $10.3892 /$ or.2019.7001

\begin{abstract}
Hypoxia-induced carbonic anhydrase IX (CAIX) is involved in intracellular and extracellular $\mathrm{pH}$ regulation, which is critical for tumor growth and metastasis. CAIX is overexpressed in breast cancer and is associated with the poor survival of patients after radiotherapy. Therefore, we evaluated the cellular and radiobiological effects of CAIX inhibition in human breast cancer cells. We used CA9 siRNA and the CA inhibitor (CAI) U104, respectively, to inhibit CAIX expression and activity in basal triple-negative MDA-MB-231 and luminal MCF-7 cells under hypoxic conditions. We investigated the effects of CAIX inhibition on CA9 mRNA and CAIX protein level, as well as on CAIX activity, intracellular $\mathrm{pH}$, proliferation, apoptosis, clonogenic survival, migration, cell cycle distribution and radiosensitivity. CA9 siRNA and CAI U104 decreased CA9 mRNA and CAIX protein level in MDA-MB-231 and MCF-7 cells. Furthermore, incubation with CAI U104 significantly decreased carbonic anhydrase activity and reduced the intracellular $\mathrm{pH}$. Additionally, CA9 siRNA or U104 reduced clonogenic survival, migration and the number of cells in the $G_{0} / G_{1}$ phase, induced apoptosis and demonstrated additive or synergistic effects in combination with irradiation. In conclusion, combination of CAIX inhibition and irradiation is a promising treatment strategy against breast cancer with hypoxia-induced CAIX expression.
\end{abstract}

Correspondence to: Dr Antje Güttler, Department of Radiotherapy, Martin Luther University of Halle-Wittenberg, 40 Ernst Grube Street, D-06120 Halle (Saale), Germany

E-mail: antje.guettler@uk-halle.de

Abbreviations: CAIX, carbonic anhydrase IX; CAI, carbonic anhydrase inhibitor; pHe, extracellular $\mathrm{pH}$; $\mathrm{pHi}$, intracellular $\mathrm{pH}$; PARP, poly(ADP-ribose)-polymerase; HPRT, hypoxanthine-guanine phosphoribosyltransferase; POLR2A, DNA-directed RNA polymerase II subunit A; BCECF, 2',7'-bis(2-carboxyethyl)-5-(and-6)-carboxyfluorescein, acetoxymethyl ester; SRB, sulforhodamine B; DMF10, dose-modifying factor 10\%; EF, enhancement factor

Key words: carbonic anhydrase IX, inhibition, radiation, breast cancer, CAIX/CA9

\section{Introduction}

Solid tumors are often characterized by hypoxic areas with a $\mathrm{pO}_{2}$ of less than $5 \mathrm{mmHg}$ (equivalent to $0.7 \% \mathrm{O}_{2}$ ) due to poor vascularization and uncontrolled growth (1). One of the most universal characteristics of solid tumors is the so called 'Warburg effect', i.e. adaption of hypoxic tumor cells' metabolism from oxidative phosphorylation to glycolysis to generate energy in the absence of oxygen (2). This adaptation increases the production of lactic acid and the generation of $\mathrm{CO}_{2}$ by neutralizing protons $\left(\mathrm{H}^{+}\right)$in the cytoplasm, a process catalyzed by carbonic anhydrases (CA). Consequently, the extracellular environment is acidified because of the export of lactic acid (monocarboxylate transporter, $\mathrm{MCT}$ ) and $\mathrm{CO}_{2}$ release from the tumor cells $(3,4)$. Tumor cells are able to adapt to the resulting acidic environment, whereas it is toxic to normal cells (4). In various tumor entities, one of the main mediators of the hypoxic response is the transcriptional factor hypoxia-inducible factor 1 (HIF-1). HIF-1 governs the cellular adaption to oxygen deficiency by regulating tumor-relevant genes involved in important processes such as glucose transport (GLUT-1), angiogenesis $(V E G F)$, proliferation $(I G F-2)$ and $\mathrm{pH}$ regulation (CA9) (5). Furthermore, the expression of membrane-bound CAIX is highly upregulated by HIF-1 $\alpha$ and catalyzes the hydration of carbon dioxide $\left(\mathrm{CO}_{2}\right)$ to bicarbonate ions $\left(\mathrm{HCO}_{3}{ }^{-}\right)$ and protons $\left(\mathrm{H}^{+}\right)(6)$. CAIX thus contributes to the acidification of the extracellular $\mathrm{pH}(\mathrm{pHe})$ under hypoxic conditions. Additionally, bicarbonate is actively transported back into cells by a sodium-dependent co-transporter, where it neutralizes $\mathrm{H}^{+}$to maintain a favorable intracellular $\mathrm{pH}(\mathrm{pHi})(7)$. Moreover, a low $\mathrm{pH}$ of the extracellular environment has been proven to influence CAIX-mediated tumor growth, invasion and metastasis (8-10). In vivo CAIX is overexpressed in many tumor entities and is associated with a poor survival of cancer patients (11). Especially in patients with invasive breast cancer, immunohistochemical CAIX expression also correlates with worse relapse-free and overall survival $(10,12,13)$. This poor prognosis may be due to hypoxia-mediated resistance to drug therapy or radiotherapy (3). Hypoxia-induced CAIX expression may also be directly linked to radioresistance. A study of breast cancer patients who received radiotherapy revealed that high CAIX expression in tumor tissue correlates with poor recurrence-free survival (14). This finding was supported by 
Table I. siRNAs and primers.

\begin{tabular}{llllcl}
\hline \multicolumn{2}{c}{ Gene } & & \multicolumn{1}{c}{ Sequence 5' $\rightarrow 3^{\prime}$} & Localization & \multicolumn{1}{c}{ Source } \\
\hline siRNAs & CA9 & Sense & 5'-CAGTGCCTATGAGCAGTTG-3' & $900-918$ & Eurofins Genomics, \\
& & Antisense & 5'-CAACTGCTCATAGGCACTG-3' & & Ebersberg, Germany \\
& \multirow{2}{*}{ Nonsense } & Sense & 5'-CGTACGCGGAATACTTCGA-3' & & \\
& & Antisense & 5'-TCGAAGTATTCCGCGTACG-3' & & \\
Primers & CA9 & Forward & 5'-GAAAACAGTGCCTATGAGCAGTTG-3' & $895-918$ & Sigma-Aldrich; Merck KGaA, \\
& & Reverse & 5'-TGCTTAGCACTCAGCATCAC-3' & $1,106-1,087$ & Darmstadt, Germany \\
& \multirow{2}{*}{ HPRT } & Forward & 5'-TTGCTGACCTGCTGGATTAC-3' & $391-410$ & \\
& & Reverse & 5'-CTTGCGACCTTGACCATCTT-3' & $652-633$ & \\
& \multirow{2}{*}{ POLR2A A } & Forward & 5'-CTTGCCCCGTGCCATGCAGA-3' & $1,358-1,377$ & \\
& Reverse & 5'-CTCGCACCCGGCCTTCCTTG-3' & $1,440-1,421$ & \\
& & &
\end{tabular}

Sequences and localization of siRNAs and primers used in this study correspond to the mRNA sequences of CA9 [NM_001216.2], HPRT [NM_000194.2] and POLR2A [NM_000937.4]. CA9, carbonic anhydrase IX; HPRT, hypoxanthine-guanine phosphoribosyltransferase; POLR2A, DNA-directed RNA polymerase II subunit A.

another recent clinical study showing that CAIX overexpression was significantly associated with poor disease-free and overall survival in a cohort of patients with triple-negative (ER', $\mathrm{PR}^{-}$and Her2-) breast cancer treated with radiotherapy, which suggests a correlation between CAIX expression and response to radiotherapy (15). Initial studies in a colorectal carcinoma xenograft model revealed that inhibiting CAIX with different CAIX inhibitors (CAI: acetazolamide, DH348 or 11c) or knockdown of $C A 9$ with shRNA delayed tumor growth and radiosensitized tumor cells $(16,17)$. Furthermore, it has been supposed that the prognostic significance of CAIX expression differs depending on the breast cancer subtype of patients (18).

In the present study, we investigated the cellular and radiobiological effects of CAIX inhibition in two human breast cancer cell lines of different subtypes: The highly invasive metastatic breast cancer cell line MDA-MB-231 (basal, triple-negative) and the less invasive non-metastatic breast cancer cell line MCF-7 (luminal, $\mathrm{ER}^{+}, \mathrm{PR}^{+}$and Her2-). In the present study, inhibition of CAIX was performed by two alternative strategies, namely treatment with CA9 siRNA or exposure to the CAIX/CAXII selective inhibitor U104, which is currently being tested in a phase I clinical trial in patients with advanced solid tumors (19). Our previous study indicated that betulin 3,28-disulfamate, which is described as a CAI by Winum et al (20), radiosensitized MDA-MB-231 breast cancer cells (21). Recently, CAI FC9403A but not CAI S4 showed synergistic effects with irradiation in MDA-MB-231 breast cancer spheroids (22). However, to the best of our knowledge, there are no studies regarding the cellular and radiobiological effects of a selective $C A 9$ knockdown with RNA interference or a CAIX/CAXII specific inhibition in human breast cancer cells. We hypothesized that selective CA9/CAIX knockdown/inhibition will decrease the proliferation, migration and clonogenic survival of both breast cancer cell lines and that the ureidosulfonamide U104 (or SLC-0111)-induced inhibition of CAIX and CAXII will cause stronger effects on radiosensitivity in breast cancer cells than RNA interference.

\section{Materials and methods}

Cell culture conditions and treatments of breast cancer cells. The breast cancer cell lines MDA-MB-231 and MCF-7 were cultured with RPMI-1640 containing $25 \mathrm{mM}$ HEPES and L-glutamine (Lonza, Walkersville, MD, USA) and supplemented with $10 \%$ fetal bovine serum (FBS; Gibco; Thermo Fisher Scientific, Inc., Waltham, MA, USA), 1\% pyruvate, $185 \mathrm{U} / \mathrm{ml}$ penicillin and $185 \mu \mathrm{g} / \mathrm{ml}$ streptomycin (Invitrogen; Thermo Fisher Scientific, Inc.) in a humidified atmosphere of $3 \% \mathrm{CO}_{2}$ at $37^{\circ} \mathrm{C}$. All experiments were conducted with cells in the logarithmic growth phase.

Twenty-four hours before treatment, the cells were seeded in cell culture flasks (Greiner Bio-One, Kremsmünster, Austria). Breast cancer cells were transfected with $100 \mathrm{nM}$ CA9 targeting siRNA (Table I) using INTERFERin ${ }^{\mathrm{TM}}$ reagent as recommended by the manufacturer (Polyplus Transfection, Illkirch, France). To inhibit CAIX activity, breast cancer cells were incubated with the CAIX inhibitor U104 (R\&D Systems, Minneapolis, MN, USA) diluted in dimethyl sulfoxide (DMSO) (Sigma-Aldrich Chemie; Merck KGaA, Darmstadt, Germany). Following treatment, the cells were exposed to hypoxia for 24 to $72 \mathrm{~h}$. To achieve hypoxic conditions $\left(0.1 \% \mathrm{O}_{2}\right)$ we used a gas generator system (Anaerocult P; Merck Millipore, Darmstadt, Germany) as previously described (23).

Irradiation was performed under hypoxic conditions $\left(0.1 \% \mathrm{O}_{2}\right) 24 \mathrm{~h}$ after treatment with $\mathrm{U} 104$ and $72 \mathrm{~h}$ after siRNA transfection. The cells were irradiated with 2,6 and $10 \mathrm{~Gy}$ at a dose rate of $2 \mathrm{~Gy} / \mathrm{min}$ accomplished with $6 \mathrm{MV}$ photons and adequate bolus material on an Elekta Synergy linear accelerator (Elekta AB, Stockholm, Sweden).

Quantitative real-time PCR ( $q P C R)$ and western blot hybridization. RNA isolation, cDNA synthesis and $\mathrm{qPCR}$ were performed as previously described (24). The primers used are cited in Table I. A no-template reaction was used as a negative control. HPRT (hypoxanthine-guanine 
phosphoribosyltransferase) and POLR2A (DNA-directed RNA polymerase II subunit A) served as housekeeping genes and were used for normalization. We used plasmid DNA standards for each gene $\left(10^{7}-10^{3}\right.$ copies $\left./ \mu \mathrm{l}\right)$ to calculated the copy number of gene of interest or the housekeeping gene.

To isolate protein, breast cancer cells were lysed in cell lysis buffer supplemented with protease inhibitors (Cell Signaling Technology, Inc., Danvers, MA, USA) and homogenized by ultrasound. The protein concentration was determined using Bradford method. The proteins were separated by gel electrophoresis [4-12\% Bis-Tris mini gels (Invitrogen; Thermo Fisher Scientific, Inc.] and transferred to a polyvinylidene difluoride (PVDF) membrane (Merck Millipore, Darmstadt, Germany). The membranes were blocked with $10 \%$ non-fat milk/TBST (50 mM NaCl, 30 mM Tris-HCl pH 8.0, 0.1\% Tween-20) and incubated with monoclonal mouse anti-CAIX antibody (dilution 1:2,000; clone no. M75; Bioscience Slovakia, Bratislava, Slovak Republic), rabbit anti-human cleaved PARP (Asp214) antibody (dilution 1:2,000; cat. no. 9541; Cell Signaling Technology, Inc.) or monoclonal mouse anti- $\beta$-actin antibody (dilution 1:10,000; cat. no. A5441; Sigma-Aldrich; Merck KGaA), followed by incubation with HRP-conjugated secondary antibodies (goat anti-rabbit, cat. no. P0448; and rabbit anti-mouse, cat. no. P0260; both diluted at 1:5,000; Dako Deutschland GmbH, Hamburg, Germany). Further washing steps were followed by the visualization of immune complexes with an ECL detection system (GE Healthcare, Chicago, IL, USA). Quantification of western blot signals was performed by the use of Image Studio Lite 5.2 software (LI-COR Biosciences, Lincoln, NE, USA).

Measurement of CAIX activity and intracellular $p H(p H i)$. Breast cancer cells were cultured under normoxic or hypoxic conditions, respectively, for $24 \mathrm{~h}$. Afterwards, hypoxic cells were treated with $50 \mu \mathrm{M}$ U104 for $3 \mathrm{~h}$. To measure CAIX activity, breast cancer cells were washed with cold isotonic buffer (130 mM NaCl, $5 \mathrm{mM} \mathrm{KCl,} 20 \mathrm{mM}$ Hepes; $\mathrm{pH}$ adjusted to $\mathrm{pH} 8.2$ at $4^{\circ} \mathrm{C}$ ), scraped down and resuspended in $2 \mathrm{ml}$ of isotonic buffer. The $\mathrm{pHe}$ was measured with a microelectrode (WTW, Weilheim, Germany) for $1 \mathrm{~min}$ before adding $1 \mathrm{ml}$ of $\mathrm{CO}_{2}$-saturated water while monitoring the $\mathrm{pH}$ every $5 \mathrm{sec}$ for $10 \mathrm{~min}$. The CAIX activity was calculated according to the Wilbur-Anderson-method (WAU/mg $=2 *(\mathrm{~T} 0-\mathrm{T}) / \mathrm{T} * \mathrm{mg}$ protein). The duration ( $\mathrm{T}$ ) to lower the $\mathrm{pH}$ of the isotonic buffer from 8.0 to 6.6 at $4^{\circ} \mathrm{C}$ was determined [T0, unanalyzed reaction (isotonic buffer); T, catalyzed reaction (e.g., normoxia, hypoxia)].

The pHi was measured with BCECF (2',7'-bis-(2-carbox yethyl)-5-(and-6)-carboxyfluorescein, acetoxymethyl ester) (Thermo Fisher Scientific, Inc.) as previously described (25). The cells were seeded on poly-lysine-treated coverslips and cultured under hypoxic conditions for $24 \mathrm{~h}$. Subsequently, the cells were incubated with $\mathrm{pH} 6.6$ ringer solution with/without $50 \mu \mathrm{M} \mathrm{U} 104$ for $3 \mathrm{~h}$ before measuring the $\mathrm{pHi}$.

Sulforhodamine B assay. The SRB assay was performed as previously described (21). MDA-MB-231 and MCF-7 cells were seeded in 96-well plates (TPP Techno Plastic Products AG, Trasadingen, Switzerland) and treated with CA9 siRNA or CAI U104 $(10,100$ and $250 \mu \mathrm{M})$ under hypoxic conditions for $72 \mathrm{~h}$. The cells were then fixed, washed and dyed with $0.4 \%$ sulforhodamine, and absorbance was measured at $540 \mathrm{~nm}$ using a GENios microplate reader (Tecan Group AG, Männedorf, Switzerland).

Clonogenic survival assay and radiosensitivity. The colony-forming assay was performed $24 \mathrm{~h}$ after incubation with the CAIX inhibitor U104 or $72 \mathrm{~h}$ after siRNA transfection under hypoxic conditions. For determination of radiosensitivity, the cells were irradiated $24 \mathrm{~h}$ (U104) and $72 \mathrm{~h}$ (siRNA) after treatment and the clonogenic survival assay was performed $1 \mathrm{~h}$ after irradiation, as previously described (26). The survival fraction is the ratio of the plating efficiencies of treated cells (e.g., siRNA treatment, irradiation) to that of control cells (e.g., nonsense siRNA, non-irradiated). Additionally, the DMF10 (dose-modifying factor $10 \%$ ), i.e., the ratio of radiation doses with or without treatment resulting in $10 \%$ survival, and the $\mathrm{EF}_{10 \mathrm{~Gy}}$ (enhancement factor), i.e., the ratio of survival fraction of treated and control cells, were determined. Data were fitted to a linear quadratic model $\left(-\ln S=\alpha \mathrm{D}+\beta \mathrm{D}^{2}\right)$ using OriginPro 8G (OriginLab Corp., Northampton, MA, USA).

Migration assay and cell cycle analysis. To analyze migration, we performed a wound scratch assay as previously described (26). In brief, cells were seeded in 24-well plates (Greiner Bio-One) and cultured until they reached $100 \%$ confluency. In detail, $24 \mathrm{~h}$ after U104 treatment and $48 \mathrm{~h}$ after siRNA transfection, respectively, the cells were wounded by creating a cell-free area with a $200-\mu 1$ pipette tip and washed twice to remove detached cells. Images were captured immediately $(0 \mathrm{~h})$ and $16 \mathrm{~h}$ after scratching to quantify the extent of the wounded area using the software Photoshop (Adobe Systems Inc., San Jose, CA, USA).

The cell cycle was analyzed $72 \mathrm{~h}$ after siRNA transfection or incubation with U104 as previously described (24). Briefly, propidium iodide (PI) was used to label DNA, and the DNA content was measured by flow cytometry on a FACScan instrument (BD Biosciences, Franklin Lakes, NJ, USA). The cell cycle phase distribution was then analyzed using the software ModFit (Verity Software House, Topsham, ME, USA).

Statistical analysis. Data represent at least three independent experiments. All data represent the mean value and standard deviation (+ SD). The significance of differences was assessed using one-way ANOVA followed by Tukey's post hoc test or Dunnett's post hoc test, or unpaired two-sided Student's t-test. A P-value $<0.05$ was considered to indicate a significant difference in reference to the population of negative control cells (nonsense siRNA or DMSO), if not otherwise indicated.

\section{Results}

CAIX expression under different cell culture conditions. We investigated CA9 mRNA and CAIX protein expression levels under different oxygen conditions $\left(21\right.$ vs. $\left.0.1 \% \mathrm{O}_{2}\right)$ and different $\mathrm{pH}$ values (pH 6.6 vs. 7.4) in the breast cancer cell lines MDA-MB-231 and MCF-7. As expected, the expression of CA9 mRNA and CAIX protein increased in both cell lines under hypoxic conditions compared to levels observed under normoxic conditions (Fig. 1). The CA9 mRNA level was significantly elevated 100 -fold under hypoxia in both breast cancer 
A

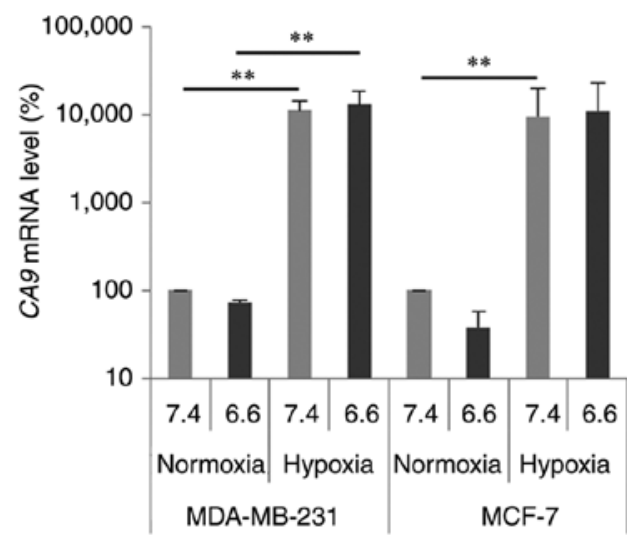

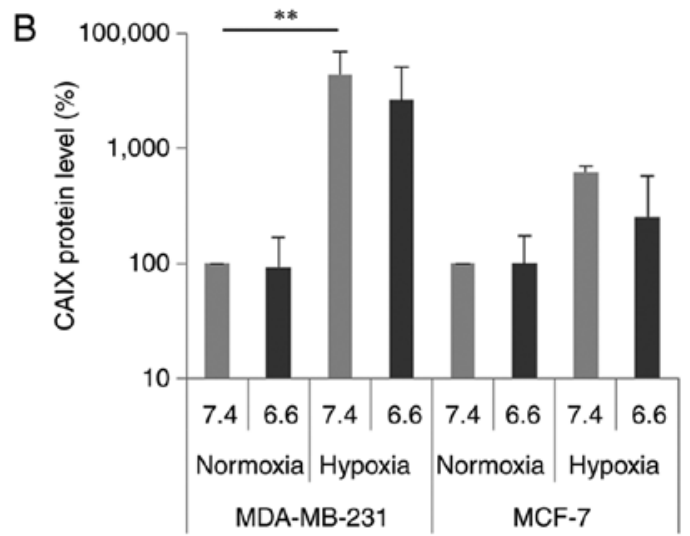

C

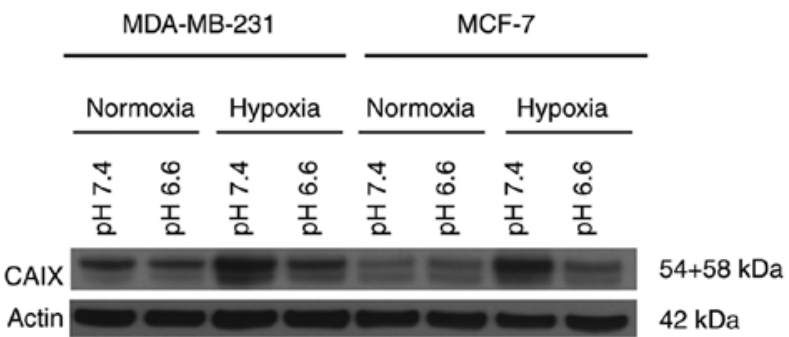

Figure 1. CA9 mRNA and CAIX protein expression level under different cell culture conditions. MDA-MB-231 and MCF-7 breast cancer cells were cultured under different conditions varying in oxygen concentration (21\% normoxia, $0.1 \%$ hypoxia) and $\mathrm{pH}$ (physiological pH: 7.4 and acidic pH: 6.6 ). The $C A 9 \mathrm{mRNA}$ (A) and CAIX protein expression levels (B) were determined with qPCR and western blotting. Intensity of CAIX western blot bands was quantified. The protein level of CAIX was normalized to equivalent protein levels of actin of each western blot band and is represented as a relative value to normoxia pH 7.4 (set as 1.0). Data represent mean values and standard deviation (+ SD) of at least three independent experiments ( $\left.{ }^{(* *} \mathrm{P}<0.01\right)$. (C) A representative western blot analysis of CAIX protein level in MDA-MB-231 and MCF-7 breast cancer cells cultured under normoxia and hypoxia with pH 7.4 and 6.6. is shown. CAIX, carbonic anhydrase IX.

cell lines (Fig. 1A, pH 7.4: MDA-MB-231: $\mathrm{P}=0.002$; MCF-7: $\mathrm{P}=0.009$ ), whereas the increase in CAIX protein level was higher in the MDA-MB-231 cells ( $\mathrm{pH}$ 7.4: 40-fold; $\mathrm{P}=0.002$ ) than that noted in the MCF-7 cells ( $\mathrm{pH}$ 7.4: 6-fold; $\mathrm{P}=0.5$ ). In addition, hypoxia-induced CAIX expression was independent of the extracellular $\mathrm{pH}$ (pHe 6.6 and 7.4) (Fig. 1B and C). Under normoxic and hypoxic conditions, CA9 mRNA levels were not significantly altered by acidic conditions (pHe 6.6) in both breast cancer cell lines (Fig. 1A). The CAIX protein level was also not influenced by the acidic medium under normoxic conditions. However, hypoxic conditions produced a trend towards reduced CAIX protein levels in both cell lines cultured in acidic medium (Fig. 1B and C).

Effects of CA9 siRNAs in breast cancer cells. RNA interference (RNAi) technique was used to transfect chemically synthesized siRNAs against $C A 9$ into breast cancer cells and the expression of CA9 mRNA and CAIX protein expression levels were examined by real-time PCR and via western blot analyses. In MDA-MB-231 and MCF-7 cells, the $C A 9$ mRNA expression levels were reduced by 79 to $87 \%(\mathrm{P}<0.01) 48 \mathrm{~h}$ after transfection with $C A 9$ siRNA (Fig. 2A). Moreover, $C A 9$ siRNA continued to suppress $C A 9$ mRNA expression $72 \mathrm{~h}$ after siRNA transfection (data not shown). Due to the long half-life of CAIX protein, we observed a strong reduction in CAIX protein level in both cell lines $72 \mathrm{~h}$ after transfection with CA9 siRNA (Fig. 2B and C). Additionally, the sulforhodamine B (SRB) assay showed that $C A 9$ knockdown did not affect the proliferation of breast cancer cells (Fig. 2E).
However, poly(ADP-ribose) polymerase (PARP) cleavage, a marker of apoptosis, increased after treatment with $C A 9$ siRNA in both cell lines (Fig. 2D). In MDA-MB-231 cells, CA9 siRNA reduced clonogenic survival by $54 \%(\mathrm{P}=0.05)$, and in MCF-7 cells, treatment with CA9 siRNA resulted in reduced clonogenic survival of $\sim 40 \%$ ( $\mathrm{P}=0.3$ ) (Fig. 3F).

In a wound scratch assay, the poorly invasive MCF-7 cells migrated to a lower extent compared to highly invasive MDA-MB-231 cells (data not shown). The migration of MDA-MB-231 cells was significantly inhibited by $50 \%$ ( $\mathrm{P}=0.008$ ) after $C A 9$ knockdown (Fig. 2G). In contrast, migration of MCF-7 cells was reduced by $20 \%$ after transfection with $C A 9$ siRNA $(\mathrm{P}=0.02)$. A subsequent flow cytometric analysis revealed that CAIX inhibition decreased the number of MDA-MB-231 cells in the $\mathrm{G}_{0} / \mathrm{G}_{1}$ phase $(\mathrm{P}=0.005)$ and increased the number of cells in the $\mathrm{G} 2 / \mathrm{M}$ phase $(\mathrm{P}=0.2)$ (Fig. 2H). In contrast, inhibition of CAIX expression in MCF-7 cells did not affect cell cycle distribution (Fig. 2H).

CAIX inhibition with U104. Inhibition of CAIX was also performed by an alternative strategy, namely treatment with the CAIX inhibitor U104, which specifically inhibits CAIX activity. Cytotoxicity assays revealed that U104 was more cytotoxic in MDA-MB-231 cells than in MCF-7 cells (Fig. 3A). The concentration that reduced survival by half $\left(\mathrm{IC}_{50}\right)$ was determined using a dose-response curve fitting. Specifically, the $\mathrm{IC}_{50}$ of $\mathrm{U} 104$ was $112.6 \pm 21.8 \mu \mathrm{M}$ in MDA-MB-231 cells, whereas in MCF-7 cells the $\mathrm{IC}_{50}$ was much higher $(306.9 \pm 37.9 \mu \mathrm{M} ; \mathrm{P}<0.001)$. The measurement of the CAIX 

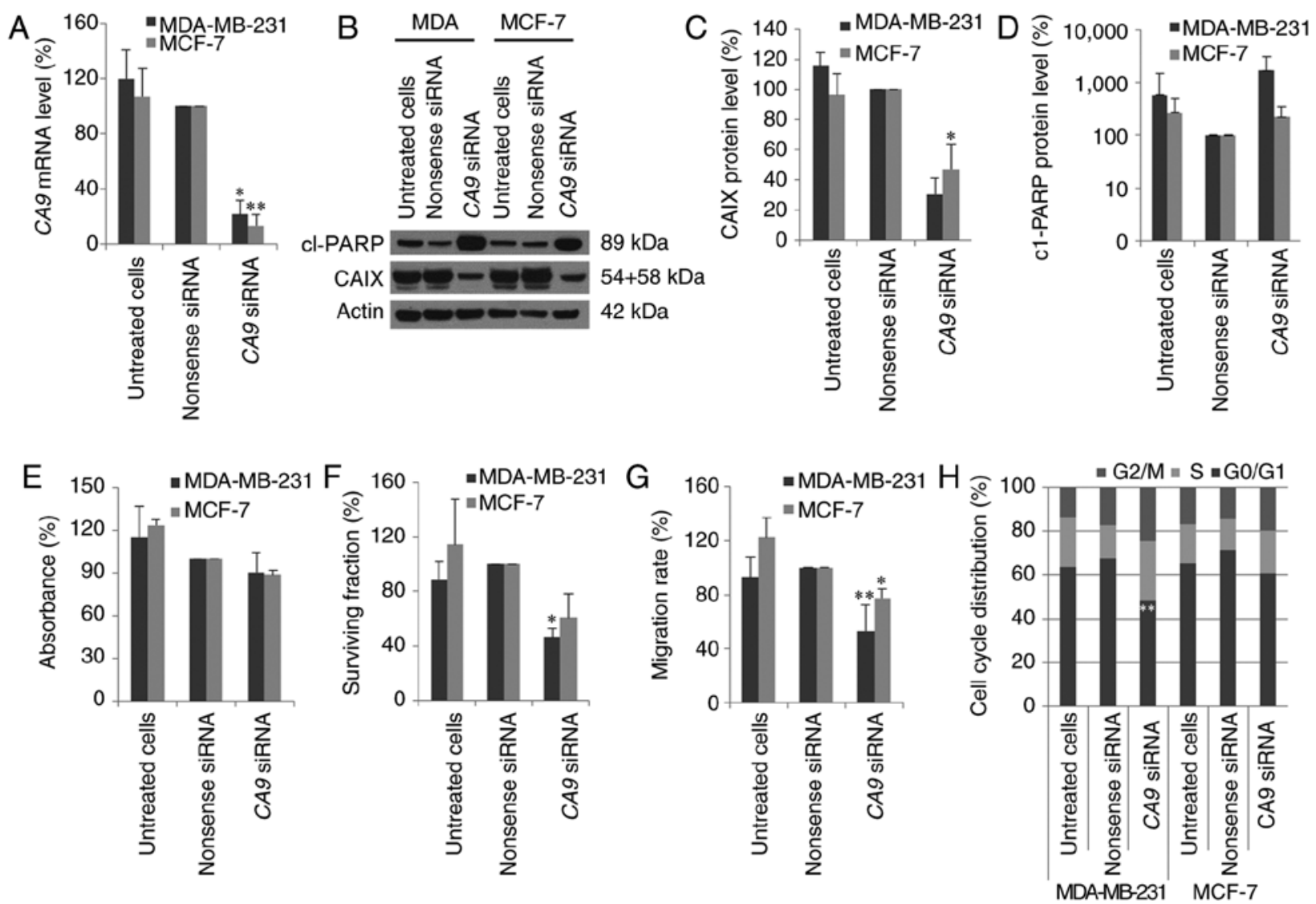

Figure 2. Effects of $C A 9$ siRNAs. MDA-MB-231 (grey bar) and MCF-7 (light grey bar) cells were transfected with $C A 9$ siRNA for 72 h under hypoxic conditions. (A) qPCR was performed to measure CA9 mRNA expression level and (B) western blotting was conducted to determine the protein level of CAIX and cleaved PARP (cl-PARP), a marker of apoptosis. For western blot analysis, one representative result of three independent experiments is shown. (C and D) Quantification of CAIX and cl-PARP protein levels is shown. Data represent protein levels of cl-PARP or CAIX, which were normalized to equivalent protein levels of actin of each western blot band and are represented as relative values to nonsense siRNA (set as 1.0). (E) The cytotoxicity of siRNA treatment was examined using SRB assay and (F) clonogenic survival using clonogenic survival assay. Additionally, the migration (G) and cell cycle distribution $(\mathrm{H})$ of breast cancer cells transfected with $C A 9$ siRNA were analyzed. Data represent mean values and standard deviation $(+\mathrm{SD})$ of at least three independent experiments (cell cycle: MCF-7: $\mathrm{n}=2)\left({ }^{*} \mathrm{P}<0.05,{ }^{* *} \mathrm{P}<0.01\right)$.

activity in MDA-MB-231 cells revealed a 2.5-fold increase in the CAIX activity under hypoxic conditions compared to normoxic conditions $(\mathrm{P}=0.002)$. Treatment with $50 \mu \mathrm{M} \mathrm{U} 104$ reduced CAIX activity to basal normoxic CAIX activity level ( $\mathrm{P}=0.002)$ (Fig. 3B). In MCF-7 cells, no change in the CAIX activity was detected after exposure to hypoxia (data not shown). Additionally, we investigated the pHi after U104 treatment. The extracellular $\mathrm{pH}(\mathrm{pHe})$ was adjusted to $\mathrm{pH}$ 6.6, and untreated MDA-MB-231 cells had a pHi of 6.71 (Fig. 3C). Treatment with $50 \mu \mathrm{M}$ U104 reduced the pHi by $0.13 \mathrm{pH}$ units to $6.58(\mathrm{P}=0.2)$. Furthermore, in MCF-7 cells a lower effect of treatment with CAI U104 on pHi was observed compared to MDA-MB-231 cells. The untreated MCF-7 cells had a pHi of 6.52 , which was reduced by $0.09 \mathrm{pH}$ units $(\mathrm{P}=0.4)$ after incubation with U104 (Fig. 3C).

Moreover, inhibition of CAIX with U104 reduced the CA9 mRNA expression level (Fig. 3D). In particular, the CA9 mRNA level in MDA-MB-231 cells was reduced by 60 and $80 \% 72 \mathrm{~h}$ after treatment with 100 and $250 \mu \mathrm{M}$ U104, respectively. In MCF-7 cells, the CA9 mRNA level was reduced to a lesser extent by 50 and $70 \% 72 \mathrm{~h}$ after treatment with 100 and $250 \mu \mathrm{M}$, respectively (Fig. 3D). Additionally, the CAIX protein level was decreased in both cell lines $72 \mathrm{~h}$ after incubation with 10 and $100 \mu \mathrm{M} \mathrm{U} 104$, and CAIX protein could no longer be detected after incubation with $250 \mu \mathrm{M}$ U104 (MDA-MB-231: $\mathrm{P}=0.0009$ ) (Fig. 3E and F). PARP cleavage was significantly increased after treatment with U104 in MDA-MB-231 cells ( $\mathrm{P}=0.001)$ (Fig. $3 \mathrm{E}$ and $\mathrm{G})$.

CAIX inhibition by U104 did not affect the clonogenic survival of MDA-MB-231 cells but reduced the clonogenic survival of MCF-7 cells by $55 \%(\mathrm{P}=0.2)$ (Fig. 4A). Incubation with U104 reduced the migration rate of MDA-MB-231 and MCF-7 cells by $52 \%(\mathrm{P}=0.008)$ and $44 \%(\mathrm{P}=0.8)$, respectively (Fig. 4B). Investigation of the cell cycle distribution of MDA-MB-231 cells revealed an increased number of cells in the $S$ phase and a statistically significantly reduced number of cells in $\mathrm{G}_{0} / \mathrm{G}_{1}(\mathrm{P}=0.02$ and $\mathrm{P}=0.01$, respectively $)$ after treatment with CAI U104 (Fig. 4C). However, CAIX inhibition with U104 increased the number of MCF-7 cells in G2/M and reduced the number of $\mathrm{MCF}-7$ cells in $\mathrm{G}_{0} / \mathrm{G}_{1}(\mathrm{P}=0.1$ and $\mathrm{P}=0.1$, respectively) (Fig. 4C).

Radiosensitivity after CAIX inhibition. Combination of CAIX inhibition by siRNA and irradiation had little or no effects on the radiosensitivity of MDA-MB-231 and MCF-7 cells, respectively (Fig. 5A and C). Specifically, a DMF10 

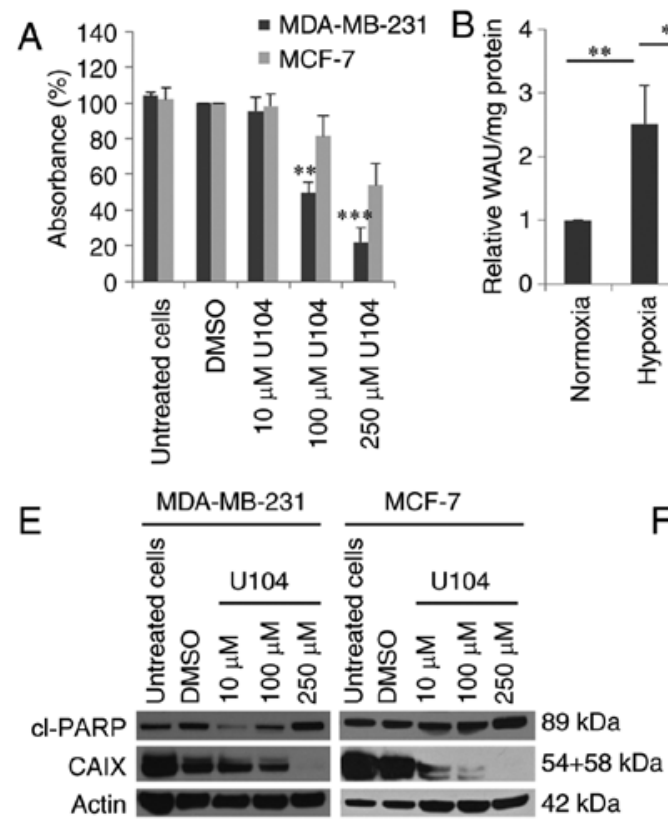
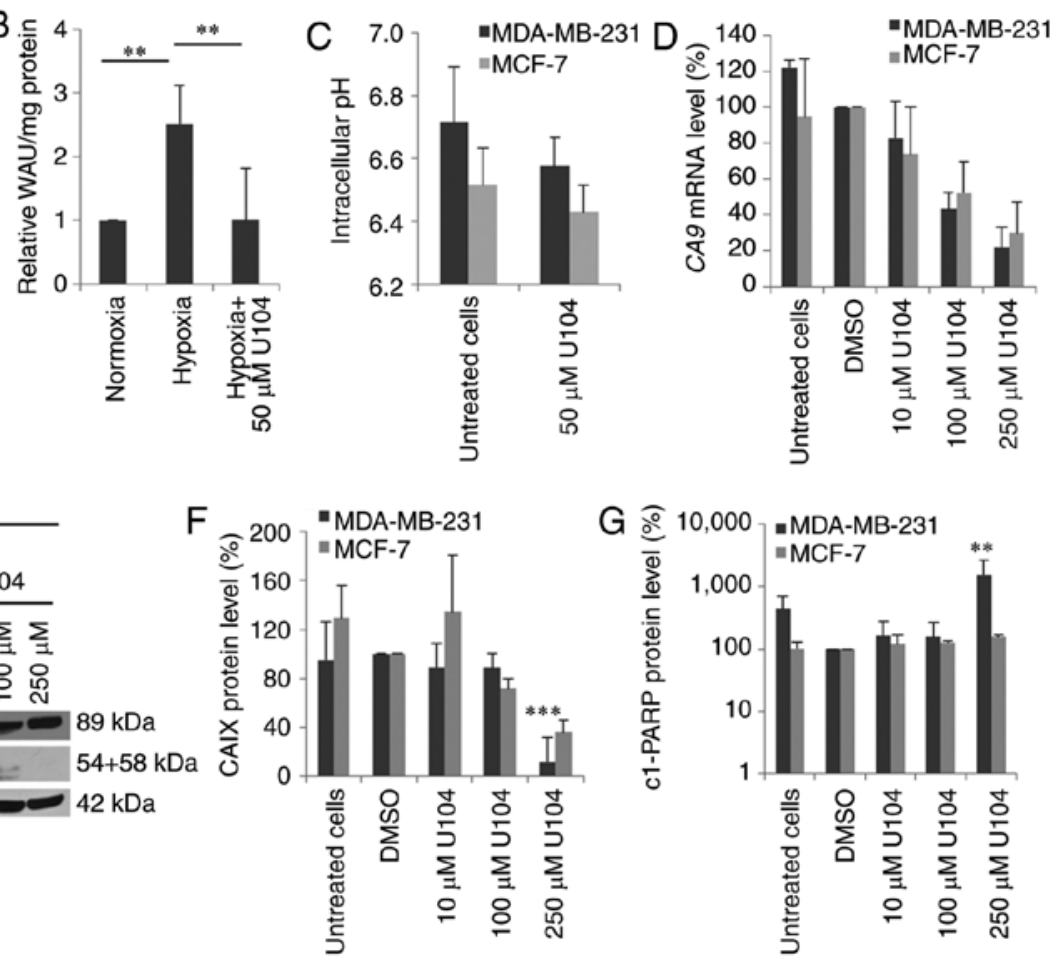

Figure 3. Effect of CAI U104 on proliferation, intracellular pH, CA9 mRNA and CAIX protein level and apoptosis. MDA-MB-231 (grey box) and MCF-7 (light grey box) cells were treated with CAI U104 under hypoxic conditions $\left(0.1 \% \mathrm{O}_{2}\right)$. (A) SRB assay was performed to determine the cytotoxicity of treatment with CAI U104. For the CAIX activity assay (B: MDA-MB-231) and intracellular pH measurement (C) breast cancer cells were treated with U104 for $3 \mathrm{~h}$. (D) qPCR was performed $72 \mathrm{~h}$ after treatment to measure the $C A 9 \mathrm{mRNA}$ expression level. (E) Western blotting was performed to measure the protein level of CAIX and cleaved PARP, a marker of apoptosis. For western blot analysis, one representative result of three independent experiments is shown. (F and G) Quantification of CAIX and cl-PARP protein level is shown. Data represent protein levels of cl-PARP or CAIX, which were normalized to equivalent protein levels of actin of each western blot band and represented as relative values to DMSO (set as 1.0). Data represent mean values and standard deviation (+ SD) of at least three independent experiments $\left({ }^{* *} \mathrm{P}<0.01,{ }^{* * *} \mathrm{P}<0.001\right)$.
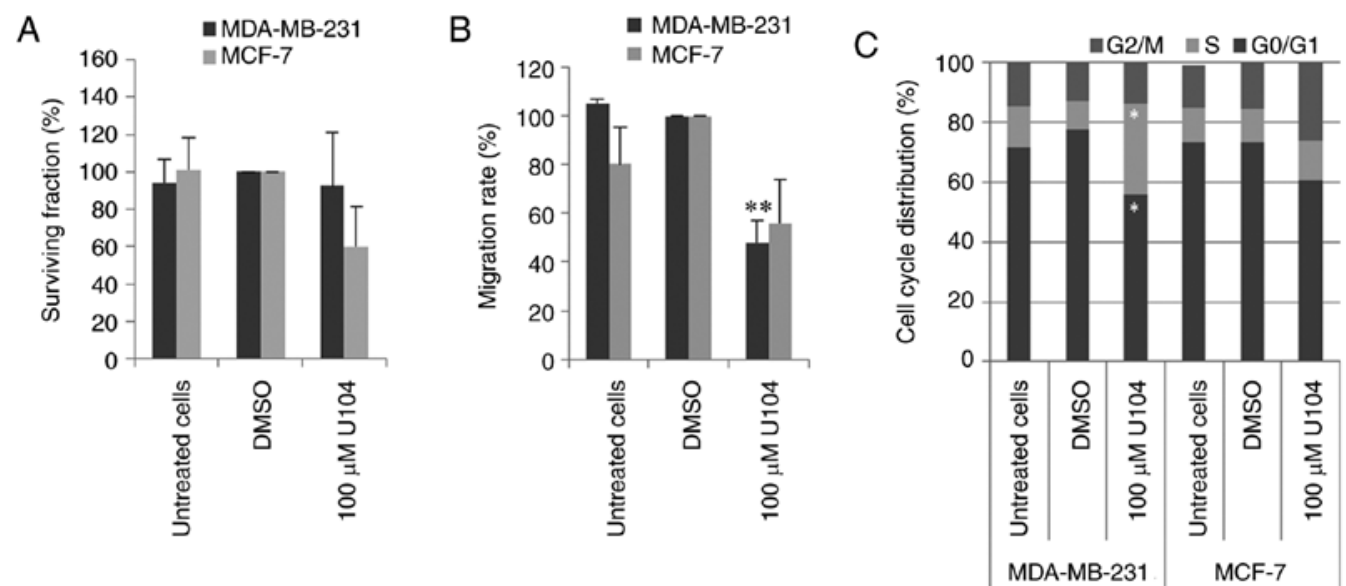

Figure 4. Effects of CAI U104 on clonogenic survival, migration and cell cycle distribution. (A) The clonogenic survival and (B) migration were assessed $24 \mathrm{~h}$ after treatment with the CAIX inhibitor U104. (C) FACS analysis was performed to specify cell cycle distribution after the inhibition of CAIX activity with U104 under hypoxic conditions in MDA-MB-231 and MCF-7 cells. Data represent mean values and standard deviation ( \pm SD) of at least three independent experiments $\left({ }^{*} \mathrm{P}<0.05,{ }^{* *} \mathrm{P}<0.01\right)$.

and $\mathrm{EF}_{10 \mathrm{~Gy}}$ of $1.10 \pm 0.17(\mathrm{P}=0.9)$ and $1.79 \pm 0.36(\mathrm{P}=0.4)$ were calculated for MDA-MB-231 cells and a DMF10 and $\mathrm{EF}_{10 \mathrm{~Gy}}$ of $0.97 \pm 0.36(\mathrm{P}=0.9)$ and $0.82 \pm 0.7(\mathrm{P}=0.9)$ for MCF-7 cells. Inhibition of CAIX with CAI U104 revealed stronger effects on the radiosensitivity of MDA-MB-231 and MCF-7 cells (Fig. 5B and D). The DMF10 and $\mathrm{EF}_{10 \mathrm{~Gy}}$ were $1.57 \pm 0.16$ $(\mathrm{P}=0.05)$ and $2.62 \pm 0.09(\mathrm{P}=0.02)$ in MDA-MB-231 cells. In
MCF-7 cells a DMF10 of $1.77 \pm 0.65(\mathrm{P}=0.2)$ and an $\mathrm{EF}_{10 \mathrm{~Gy}}$ of $4.27 \pm 2.80(\mathrm{P}=0.1)$ was calculated.

\section{Discussion}

Hypoxia-regulated protein carbonic anhydrase IX (CAIX) is associated with tumor-relevant processes, such as migration, 
A

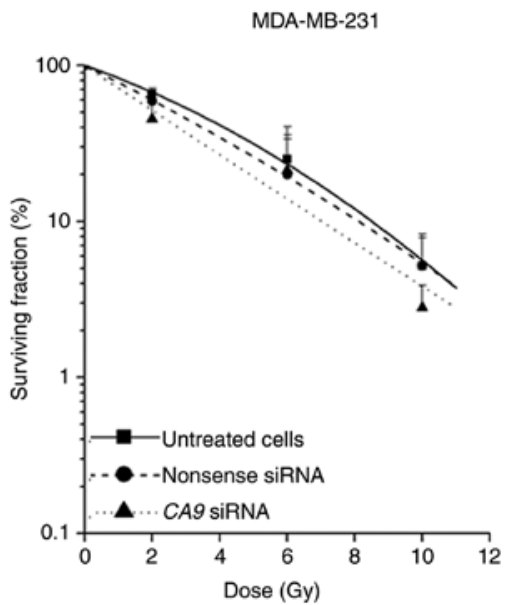

C

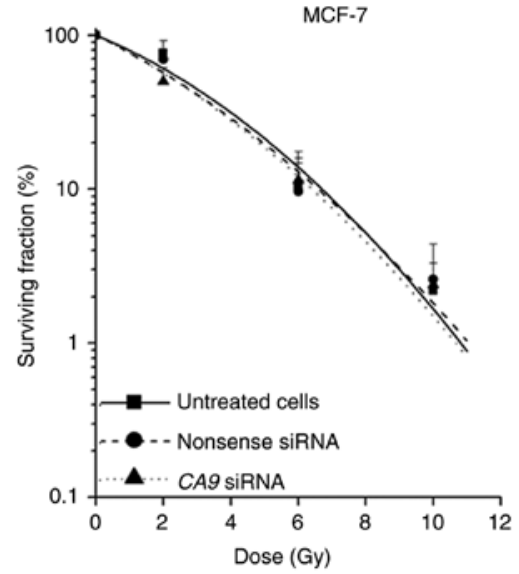

B

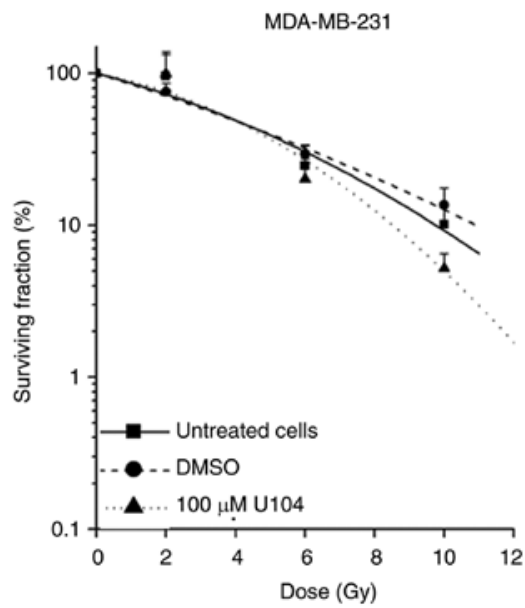

D

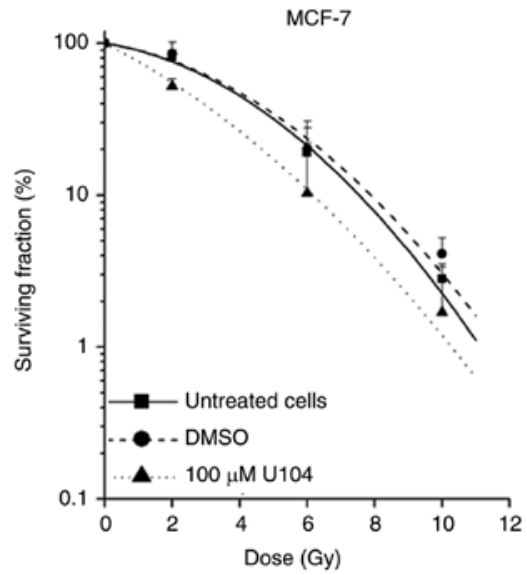

Figure 5. Radiosensitivity of breast cancer cells. (A and B) MDA-MB-231 and (C and D) MCF-7 cells were irradiated with 2, 6 and 10 Gy under hypoxic conditions after CAIX inhibition with CA9 siRNA (A and C) and CAI U104 (B and D). Data represent mean values and standard deviation ( \pm SD) of at least three independent experiments.

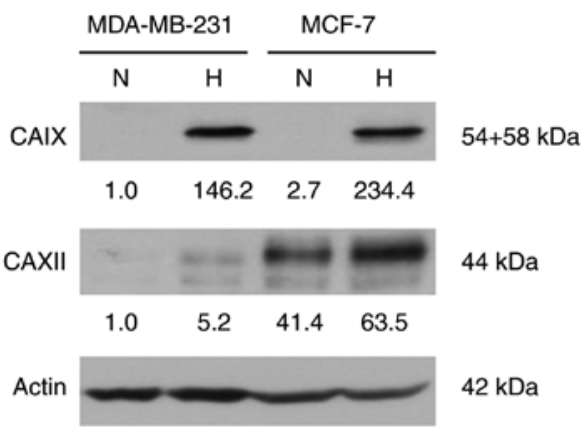

Figure 6. CAIX and CAXII protein expression in breast cancer cell lines. MDA-MB-231 and MCF-7 cells were cultured under normoxic $(\mathrm{N})$ and hypoxic $(\mathrm{H})$ conditions for $72 \mathrm{~h}$. Western blotting was conducted to determine the protein levels of CAIX and CAXII. Four independent experiments were conducted. Representative western blots are shown. Quantified western blot bands of CAIX and CAXII were normalized to actin protein levels and represented as relative values to protein level of MDA-MB-231 cells under normoxic conditions set as 1.0 .

proliferation and invasion and its expression correlates with the prognosis of cancer patients $(27,28)$. Although CAIX is primarily responsible for the acidification of the tumor environment, we did not identify an altered $C A 9$ mRNA expression but a slightly reduced CAIX protein level in response to acidic (pH 6.6) and hypoxic $\left(0.1 \% \mathrm{O}_{2}\right)$ culture conditions in both breast cancer cell lines (Fig. 1). Recently, we detected similar effects in AT1 prostate cancer cells (29). In contrast to our investigations, Tang et al observed a decrease in CA9 mRNA level in MCF-7 cells after incubation with lactic acid under hypoxic conditions (30). On the other hand, we previously showed that the response of CAIX expression to acidic conditions (upregulated or downregulated) depends on the cell line (31). For example, culturing glioblastoma and osteosarcoma cells under acidic conditions ( $\mathrm{pH}$ 6.4) increased CA9 gene transcription and CAIX protein level under normoxic and hypoxic conditions $(32,33)$. Therefore, acidic conditions-in contrast to hypoxia-have different, cell-type specific consequences in human tumor cells.

With RNA interference and CAI U104, two different strategies were used to target CAIX under hypoxic conditions in two breast cancer cell lines. Both methods resulted in decreased CA9 mRNA and CAIX protein levels (Figs. 2 and 3). These effects are in line with previous reports that also demonstrated reductions in CA9 mRNA and CAIX protein level in tumor cells in response to treatment with RNA interference or CAI U104 (10,21,22,34-36). CAI-induced changes were attributed to the possible degradation or internalization of CAIX $(21,36)$. In addition, treatment with CAI U104 decreased the pHi and reduced CAIX activity in MDA-MB-231 breast cancer cells (Fig. 3B and C). Accordingly, the pHi of CAIX-expressing 
fibroblasts was previously shown to be more alkaline than the pHi of fibroblasts that do not express CAIX (8). Contrary to MDA-MB-231 cells, a hypoxia-induced increase in CAIX activity was lacking in MCF-7 breast cancer cells. It is conceivable that the CAIX activity assay is insufficiently sensitive for measurement of this slight increase of CAIX protein level in MCF-7 cells after hypoxic exposure. In agreement with this, Meehan et al detected only partial activation of HIF signaling in acutely hypoxic MCF-7 cells (22).

In the present study, RNA interference or CAI U104 affected migration, clonogenic survival, cell cycle distribution and apoptosis in both breast cancer cell lines (Figs. 2-4). Other studies investigating various ureido-sulfamate CAIX inhibitors also revealed a reduction in the migration, invasion or metastasis of breast cancer cells in vitro or in xenograft models (10,37). In soft tissue sarcoma cells (HT-1080), the depletion of CAIX expression decreased migration, invasion and expansive growth (9). CAIX influences the expression of genes that regulate several processes, such as cell motility, cell-cell contact, focal adhesion formation and epithelial-mesenchymal transition (38). In cervical carcinoma cells, CAIX increased migration and invasion via the $C A 9$-dependent inactivation of Rho-GTPase (39). However, CA9 knockdown did not affect the proliferation of breast cancer cells after 3 days (Fig. 2E). Initial studies of breast cancer cell lines revealed that silencing of $C A 9$ with siRNAs inhibited long-term proliferation (after 6 days) and clonogenic survival under hypoxic conditions (34). In confirmation with our results concerning ureidosulfonamide U104, Dubois et al observed a decrease in proliferation and induction of apoptosis after inhibiting CAIX in colorectal cancer (16). The decreased pHi may be responsible for the decreased proliferation and increased apoptosis rate $(16,28)$. This study of rat prostate cancer cells confirmed the intracellular acidification, anti-proliferative and pro-apoptotic effects of CAIX inhibition with CAI U104 (29). In addition, recently, our previous results confirmed CAI-induced apoptosis for betulinyl sulfamates in MDA-MB-231 and MCF7 cells using different methods $(21,40)$. A further study detected CAI-induced apoptosis in different cancer cell lines (41). However, the molecular mechanism underlying this effect remains to be elucidated.

The effects of RNA interference or CAI U104 were even stronger in the basal triple-negative MDA-MB-231 breast cancer cells compared to luminal MCF-7 cells (Figs. 2-4). In agreement with our results, silencing of $C A 9$ with shRNA revealed a stronger inhibition of invasion and increased doxorubicin-mediated reduction of spheroid-forming ability in triple-negative MDA-MB-231 cells compared to breast cancer cell lines with other subtypes (18). In addition, the prognostic significance of the CA9 mRNA level differed depending on the subtype of breast cancer (18). For generalization of these effects, further breast cancer cell lines with each intrinsic breast cancer subtype must be analyzed.

We determined additive/synergistic effects after $C A 9$ knockdown or U104-induced CAIX inhibition in combination with irradiation in MDA-MB-231 and MCF-7 breast cancer cells under hypoxic conditions (Fig. 5). Initial studies of a colorectal carcinoma xenograft model revealed that CAIX inhibition with different CAIX inhibitors (CAI: Acetazolamide, DH348 or 11c) or CA9 knockdown by
shRNA delayed tumor growth and radiosensitized tumor cells $(16,17)$. These findings corroborate other studies showing that inhibition of carbonic anhydrases with different CAIs radiosensitized different tumor cell lines $(21,35,42)$. This effect may be due to the reduced acidification of the extracellular environment $(16,17)$ or the intracellular acidification (Fig. 3C) caused by CAIX inhibition. Fibroblasts lacking CAIX were strongly radiosensitized when cultured under acidic conditions ( $\mathrm{pH}$ 7.0) compared to normal conditions $(\mathrm{pH} 7.5)$ because they cannot maintain their intracellular $\mathrm{pH}$ (42). However, this effect could be abrogated by stably transfecting cells with CAIX. In further studies we plan investigations with stable knockdown of the CAIX gene in mammary carcinoma cell lines. It should be noted that the effects of CAI U104 on radiosensitization were stronger than the effects caused by RNAi, especially in MCF-7 cells. The isoenzyme CAXII is expressed at higher levels in MCF-7 cells compared to MDA-MB-231 cells under normoxic and hypoxic conditions (Fig. 6). The effects of CAIX inhibition by siRNA may be compensated by CAXII, since siRNA selectively inhibited $C A 9$, not $C A 12$ mRNA expression. However, CAI U104 inhibited activity of both isoenzymes CAIX and CAXII and therefore caused stronger effects on radiosensitivity (10). In accordance with that, combined knockdown of $C A 9$ and $C A 12$ gene expression revealed stronger radiosensitization of colon carcinoma cells than single knockdown of $C A 9$ or $C A 12$ gene expression (42). Due to possible compensatory effects of CAXII, investigation of CAXII function in tumor relevant processes is warranted.

In summary, it was demonstrated that specifically targeting CA9 or inhibiting CAIX/CAXII activity influences intracellular and extracellular $\mathrm{pH}$ that is important for clonogenic survival, apoptosis, migration and radiosensitivity of both breast cancer cell lines. CAIX alone and in combination with CAXII are significant targets for novel combination strategies with radiotherapy in breast cancer.

\section{Acknowledgements}

We would like to thank our colleagues from the Department of Radiotherapy and the Julius Bernstein Institute of Physiology for their contribution to this study and their continuous support. We would also like to thank Gabriele Thomas, Kathrin Theile and Sarah Reime for their excellent technical assistance.

\section{Funding}

The present study was supported by the Wilhelm Sander Stiftung (grant no. FKZ: 2013.090.1).

\section{Availability of data and materials}

The datasets used during the present study are available from the corresponding author upon reasonable request.

\section{Authors' contributions}

AG designed the study, performed the experimental procedures, analyzed the data and drafted the manuscript. KT 
performed the experimental procedures and analyzed the data. AR, HW and JK substantially contributed to the data acquisition and interpretation and reviewed the manuscript. OT, MB and DV designed the study, substantially contributed to the acquisition and interpretation of the data and reviewed the manuscript. All authors read and approved the manuscript and agree to be accountable for all aspects of the research in ensuring that the accuracy or integrity of any part of the work are appropriately investigated and resolved.

\section{Ethics approval and consent to participate}

Not applicable.

\section{Patient consent for publication}

Not applicable.

\section{Competing interests}

The authors state that they have no competing interests.

\section{References}

1. Brown JM and Wilson WR: Exploiting tumour hypoxia in cancer treatment. Nat Rev Cancer 4: 437-447, 2004.

2. Warburg O: On the origin of cancer cells. Science 123: 309-314, 1956.

3. Gatenby RA and Gillies RJ: Why do cancers have high aerobic glycolysis? Nat Rev Cancer 4: 891-899, 2004.

4. Brown JM and Giaccia AJ: The unique physiology of solid tumors: Opportunities (and problems) for cancer therapy. Cancer Res 58: 1408-1416, 1998.

5. Semenza GL: Targeting HIF-1 for cancer therapy. Nat Rev Cancer 3: 721-732, 2003.

6. Wykoff CC, Beasley NJ, Watson PH, Turner KJ, Pastorek J, Sibtain A, Wilson GD, Turley H, Talks KL, Maxwell PH, et al: Hypoxia-inducible expression of tumorassociated carbonic anhydrases. Cancer Res 60: 7075-7083, 2000.

7. Swietach P, Vaughan-Jones RD and Harris AL: Regulation of tumor $\mathrm{pH}$ and the role of carbonic anhydrase 9. Cancer Metastasis Rev 26: 299-310, 2007.

8. Lou Y, McDonald PC, Oloumi A, Chia S, Ostlund C, Ahmadi A, Kyle A, Auf dem Keller U, Leung S, Huntsman D, et al: Targeting tumor hypoxia: Suppression of breast tumor growth and metastasis by novel carbonic anhydrase IX inhibitors. Cancer Res 71: 3364-3376, 2011

9. Radvak P, Repic M, Svastova E, Takacova M, Csaderova L, Strnad H, Pastorek J, Pastorekova S and Kopacek J: Suppression of carbonic anhydrase IX leads to aberrant focal adhesion and decreased invasion of tumor cells. Oncol Rep 29: 1147-1153, 2013.

10. Chiche J, Ilc K, Laferrière J, Trottier E, Dayan F, Mazure NM, Brahimi-Horn MC and Pouysségur J: Hypoxia-inducible carbonic anhydrase IX and XII promote tumor cell growth by counteracting acidosis through the regulation of the intracellular pH. Cancer Res 69: 358-368, 2009.

11. van Kuijk SJA, Yaromina A, Houben R, Niemans R, Lambin $P$ and Dubois LJ: Prognostic significance of carbonic anhydrase IX expression in cancer patients: A meta-analysis. Front Oncol 6: 69, 2016.

12. Hussain SA, Ganesan R, Reynolds G, Gross L, Stevens A, Pastorek J, Murray PG, Perunovic B, Anwar MS, Billingham L, et al: Hypoxia-regulated carbonic anhydrase IX expression is associated with poor survival in patients with invasive breast cancer. Br J Cancer 96: 104-109, 2007.

13. Chia SK, Wykoff CC, Watson PH, Han C, Leek RD, Pastorek J, Gatter KC, Ratcliffe P and Harris AL: Prognostic significance of a novel hypoxia-regulated marker, carbonic anhydrase IX, in invasive breast carcinoma. J Clin Oncol 19: 3660-3668, 2001.
14. Brennan DJ, Jirstrom K, Kronblad A, Millikan RC, Landberg G, Duffy MJ, Rydén L, Gallagher WM and O'Brien SL: CA IX is an independent prognostic marker in premenopausal breast cancer patients with one to three positive lymph nodes and a putative marker of radiation resistance. Clin Cancer Res 12: 6421-6431, 2006.

15. Jin MS, Lee H, Park IA, Chung YR, Im SA, Lee KH, Moon HG, Han W, Kim K, Kim TY, et al: Overexpression of HIF1 $\alpha$ and CAXI predicts poor outcome in early-stage triple negative breast cancer. Virchows Arch 469: 183-190, 2016.

16. Dubois L, Peeters SG, van Kuijk SJ, Yaromina A, Lieuwes NG, Saraya R, Biemans R, Rami M, Parvathaneni NK, Vullo D, et al: Targeting carbonic anhydrase IX by nitroimidazole based sulfamides enhances the therapeutic effect of tumor irradiation: A new concept of dual targeting drugs. Radiother Oncol 108: 523-528, 2013.

17. Dubois L, Peeters S, Lieuwes NG, Geusens N, Thiry A, Wigfield S, Carta F, McIntyre A, Scozzafava A, Dogné JM, et al: Specific inhibition of carbonic anhydrase IX activity enhances the in vivo therapeutic effect of tumor irradiation. Radiother Oncol 99: 424-431, 2011.

18. Ivanova L, Zandberga E, Silina K, Kalnina Z, Ābols A, Endzeliņ̌s E, Vendina I, Romanchikova N̉, Hegmane A, Trapencieris $\mathrm{P}$, et al: Prognostic relevance of carbonic anhydrase IX expression is distinct in various subtypes of breast cancer and its silencing suppresses self-renewal capacity of breast cancer cells. Cancer Chemother Pharmacol 75: 235-246, 2015.

19. McDonald PC, Chafe SC and Dedhar S: Overcoming hypoxia-mediated tumor progression: Combinatorial approaches targeting $\mathrm{pH}$ regulation, angiogenesis and immune dysfunction. Front Cell Dev Biol 4: 27, 2016.

20. Winum JY, Pastorekova S, Jakubickova L, Montero JL, Scozzafava A, Pastorek J, Vullo D, Innocenti A and Supuran CT: Carbonic anhydrase inhibitors: Synthesis and inhibition of cytosolic/tumor-associated carbonic anhydrase isozymes I, II, and IX with bis-sulfamates. Bioorg Med Chem Lett 15: 579-584, 2005.

21. Bache M, Münch C, Güttler A, Wichmann H, Theuerkorn K, Emmerich D, Paschke R and Vordermark D: Betulinyl sulfamates as anticancer agents and radiosensitizers in human breast cancer cells. Int J Mol Sci 16: 26249-26262, 2015.

22. Meehan J, Ward C, Turnbull A, Bukowski-Wills J, Finch AJ, Jarman EJ, Xintaropoulou C, Martinez-Perez C, Gray M, Pearson $\mathrm{M}$, et al: Inhibition of $\mathrm{pH}$ regulation as a therapeutic strategy in hypoxic human breast cancer cells. Oncotarget 8: 42857-42875, 2017.

23. Kessler J, Hahnel A, Wichmann H, Rot S, Kappler M, Bache M and Vordermark D: HIF-1 $\alpha$ inhibition by siRNA or chetomin in human malignant glioma cells: Effects on hypoxic radioresistance and monitoring via CA9 expression. BMC Cancer 10: 605,2010

24. Güttler A, Giebler M, Cuno P, Wichmann H, Keßler J, Ostheimer C, Söling A, Strauss C, Illert J, Kappler M, et al: Osteopontin and splice variant expression level in human malignant glioma: Radiobiologic effects and prognosis after radiotherapy. Radiother Oncol 108: 535-540, 2013.

25. Riemann A, Ihling A, Thomas J, Schneider B, Thews O and Gekle M: Acidic environment activates inflammatory programs in fibroblasts via a cAMP-MAPK pathway. Biochim Biophys Acta 1853: 299-307, 2015.

26. Hahnel A, Wichmann H, Kappler M, Kotzsch M, Vordermark D, Taubert $\mathrm{H}$ and Bache M: Effects of osteopontin inhibition on radiosensitivity of MDA-MB-231 breast cancer cells. Radiat Oncol 5: 82, 2010.

27. McDonald PC, Winum JY, Supuran CT and Dedhar S: Recent developments in targeting carbonic anhydrase IX for cancer therapeutics. Oncotarget 3: 84-97, 2012.

28. Pastorek $\mathbf{J}$ and Pastorekova $\mathbf{S}$ : Hypoxia-induced carbonic anhydrase IX as a target for cancer therapy: From biology to clinical use. Semin Cancer Biol 31: 52-64, 2015.

29. Riemann A, Güttler A, Haupt V, Wichmann H, Reime S, Bache M, Vordermark D and Thews O: Inhibition of carbonic anhydrase IX by ureidosulfonamide inhibitor U104 reduces prostate cancer cell growth, but does not modulate daunorubicin or cisplatin cytotoxicity. Oncol Res 26: 191-200, 2018.

30. Tang X, Lucas JE, Chen JL, LaMonte G, Wu J, Wang MC, Koumenis C and Chi JT: Functional interaction between responses to lactic acidosis and hypoxia regulates genomic transcriptional outputs. Cancer Res 72: 491-502, 2012. 
31. Vordermark D, Kaffer A, Riedl S, Katzer A and Flentje M Characterization of carbonic anhydrase IX (CA IX) as an endogenous marker of chronic hypoxia in live human tumor cells. Int J Radiat Oncol Biol Phys 61: 1197-1207, 2005.

32. Matsubara T, Diresta GR, Kakunaga S, Li D and Healey JH: Additive influence of extracellular $\mathrm{pH}$, oxygen tension, and pressure on invasiveness and survival of human osteosarcoma cells. Front Oncol 3: 199, 2013.

33. Ihnatko R, Kubes M, Takacova M, Sedlakova O, Sedlak J, Pastorek J, Kopacek J and Pastorekova S: Extracellular acidosis elevates carbonic anhydrase IX in human glioblastoma cells via transcriptional modulation that does not depend on hypoxia. Int J Oncol 29: 1025-1033, 2006.

34. Said HM, Hagemann C, Carta F, Katzer A, Polat B, Staab A Scozzafava A, Anacker J, Vince GH, Flentje M and Supuran CT: Hypoxia induced CA9 inhibitory targeting by two different sulfonamide derivatives including acetazolamide in human glioblastoma. Bioorg Med Chem 21: 3949-3957, 2013.

35. Duivenvoorden WCM, Hopmans SN, Gallino D, Farrell T, Gerdes C, Glennie D, Lukka H and Pinthus JH: Inhibition of carbonic anhydrase IX (CA9) sensitizes renal cell carcinoma to ionizing radiation. Oncol Rep 34: 1968-1976, 2015.

36. Robertson N, Potter C and Harris AL: Role of carbonic anhydrase IX in human tumor cell growth, survival, and invasion. Cancer Res 64: 6160-6165, 2004.
37. Ward C, Meehan J, Mullen P, Supuran C, Dixon JM, Thomas JS, Winum J-Y,Lambin P, Dubois L, Pavathaneni NK, et al: Evaluation of carbonic anhydrase IX as a therapeutic target for inhibition of breast cancer invasion and metastasis using a series of in vitro breast cancer models. Oncotarget 6: 24856-24870, 2015.

38. Sedlakova O, Svastova E, Takacova M, Kopacek J, Pastorek J and Pastorekova S: Carbonic anhydrase IX, a hypoxia-induced catalytic component of the $\mathrm{pH}$ regulating machinery in tumors. Front Physiol 4: 400, 2014.

39. Shin HJ, Rho SB, Jung DC, Han IO, Oh ES and Kim JY: Carbonic anhydrase IX (CA9) modulates tumor-associated cell migration and invasion. J Cell Sci 124: 1077-1087, 2011.

40. Vanchanagiri K, Emmerich D, Bruschke M, Bache M, Seifert F, Csuk R, Vordermark D and Paschke R: Synthesis and biological investigation of new carbonic anhydrase IX (CAIX) inhibitors. Chem Biol Interact 284: 12-23, 2018.

41. Cianchi F, Vinci MC, Supuran CT, Peruzzi B, De Giuli P, Fasolis G, Perigli G, Pastorekova S, Papucci L, Pini A, et al: Selective inhibition of carbonic anhydrase IX decreases cell proliferation and induces ceramide-mediated apoptosis in human cancer cells. J Pharmacol Exp Ther 334: 710-719, 2010.

42. Doyen J, Parks SK, Marcié S, Pouysségur J and Chiche J: Knock-down of hypoxia-induced carbonic anhydrases IX and XII radiosensitizes tumor cells by increasing intracellular acidosis. Front Oncol 2: 199, 2013. 